\title{
SCREENING STUDY OF IODINE DEFICIENCY STATUS AND THYROID DISEASES IN GEORGIAN CHILDREN
}

\author{
L. Uchava ${ }^{1}$, S. Janjgava ${ }^{1}$, E. Giorgadze ${ }^{1}$, K. Asatiani ${ }^{2}$, M. Lomidze ${ }^{2}$, M. Korinteli ${ }^{2}$, T. Zerekidze ${ }^{1}$, K. \\ Mirianashvili $^{2}$, N. Svani ${ }^{2}$, A. Malazonia ${ }^{2}$ \\ ${ }^{I}$ Department of Endocrinology, LTD 'Healthy Life', Tbilisi State University, ${ }^{2}$ LTD 'Healthy Life', Tbilisi, \\ Georgia
}

Background and aims: Thyroid disorders are the second commonly encountered disorders in endocrine clinics and are significant causes of medical morbidity and mortality. Thyroid disorders are widely recognized as an important public health problem; its prevalence has increased substantially in the recent decades. The relationship between Thyroid disorders and childhood are one of the longest running controversies in endocrinology. The objective of the study are screening of iodine deficiency and thyroid diseases in Georgian children.

Materials and methods: 21118 children with age range 6-16 years were included in the study. Children were screened by Palpation and ultrasonography of the thyroid gland, after that, with children who have had a change were made: TSH and Anti-TPO. According to the laboratory and clinical condition we divided patients into five groups:

1) children without changes,

2) children with hypothyroidism,

3) children with hyperthyroidism,

4) children with nodular goiter and

5) children with autoimmune thyroiditis.

Results: The patients were distributed in the following way:

1) children without changes 15301 ,

2) children with hypothyroidism 4578 ,

3) children with hyperthyroidism 285 ,

4) children with nodular goiter 43 and

5) children with autoimmune thyroiditis 911.

The appropriate treatment according to the laboratory and clinical condition was prescribed to all patients.

Conclusion: Thyroid gland diseases are an important medical and epidemiologic entity, as its deleterious effects on patients is firmly established. Children thyroid gland diseases may represent another physiological aberration. As our study demonstrated thyroid gland diseases in Georgian children is one of the major problem. 